\title{
Basic psychosomatic concepts
}

\author{
HeINZ H. WOLFF \\ M.D., F.R.C.P. \\ Consultant Psychiatrist, The Bethlem Royal and Maudsley Hospitals, London, S.E.5, \\ and University College Hospital, London, W.C.1
}

\section{Meaning of the term psychosomatic}

There has been a gradual change in the use of the term psychosomatic and in research in the area of psychosomatic medicine. The use of the term itself has been critically examined by Lewis (1967), and its usefulness has been questioned on the grounds that it separates psyche from soma and thus perpetuates the Cartesian concept of mind-body dualism. Such theoretical issues need no longer concern us provided we accept two basic facts.

Firstly, no scientist will deny nowadays that all mental phenomena are based on physical processes in the brain; in this sense mind-body dualism is an out-of-date concept. Every human experience can be looked upon either from a psychological or physical point of view depending on whether we are studying the experience and its meaning in its psychosocial context or whether we are engaged in a study of the physiological mechanisms which underly human experience and behaviour (Wolff, 1968; Hill, 1970a).

Secondly, it is equally apparent that the subjective experience of mental events-perceptions, feelings, thoughts, fantasies, wishes and awareness of our own behaviour-constitutes a personal psychic reality, and even the most complete description of the corresponding brain processes in physical terms cannot convey the nature or meaning of this experience. In this sense the experience of mental phenomena is of a different category from its physiological correlate (Wolff, 1968; Lipowski, 1968). As Harré (1970) in his book on The Principles of Scientific Thinking has put it 'our awareness of mind-states and of brainstates differ as two different ways of knowing about the same thing'. Both psychological and physical phenomena need to be studied but the methods of observation are different in each case. Physiological and biochemical investigations are the methods appropriate to research on the biological mechanisms whilst psychological procedures are required in research on mental phenomena. The study of the inter-relationship between these two fields of investigation, the biological and psychological, constitutes the field of psychosomatics in its widest sense, and it has its applications in healthy human functioning as well as in disease.

\section{Psychosomatic disorder or psychosomatic approach?}

When the term psychosomatic is applied in relation to medicine, it therefore has a wider meaning than it used to have. Psychosomatic medicine is no longer confined to the study of a few conditions, the so-called psychosomatic disorders, in whose origin emotional factors were thought to play a particularly important aetiological or precipitating role; instead it is used to describe an approach to the whole field of medicine, psychiatry included, in which the interaction between biological, psychological and social factors is given due attention in every patient (Engel, 1967). The rapid advances in our understanding of physical mechanisms and causes of disease and of physical treatment procedures have led to a relative neglect of the consideration of the psychosocial aspects of illness, especially in hospital practice. General practitioners and psychiatrists tend to be more aware of the interplay between psychosocial and physical aspects of illness as they affect the individual patient than some of their medical colleagues; the need to apply a psychosomatic approach to every patient, whatever illness, physical or mental, he may be suffering from, has therefore been stressed particularly by them.

On the other hand, several of the earlier workers in the psychosomatic field tended to approach the subject from a somewhat one-sided psychoanalytic point of view (Wolff, 1968) which led them to postulate that in certain diseases like bronchial asthma, peptic ulcer or ulcerative colitis there exists either a particular personality structure (Dunbar, 1943) or emotional conflict situation (Alexander \& French, 1948; Alexander, French \& Pollock, 1968) which was supposed to be specific for the particular condition; as has been pointed out by Schmale (1969), they also tended uncritically to apply the concepts of conversion and symbolism which are basic to the understanding of hysterical conversion symptoms (Breuer \& Freud, 1895) to structural organic lesions. These earlier approaches, whilst stimulating interest 
in the field, often ignored the equally important biological aspects of these disorders. The present day psychosomatic approach which combines biological considerations with psychological and social ones, and studies their interaction in disease states as they affect man as a psycho-biological organism in his social setting, is more likely to advance progress, and is in fact applicable to the whole field of medical practice. The manner in which this approach is being developed in different countries has been reviewed by Wittkower et al. (1969).

\section{Psychological studies and observations}

The fact that the methods of clinical enquiry and research in the psychological sphere differ from those employed in organic medicine has given rise to certain practical and theoretical difficulties. The organic aspects are concerned with physical mechanisms, and research procedures, based as they are on physiological, biochemical and pathological studies, are concerned not with whole persons but with parts of the body, the structure and function of organs and cells and their components, and with biochemical processes and their interaction. Those who work in this biological field, therefore, use methods of observation, measurement and experimentation which are similar to those used in the physical sciences, and they are often unfamiliar with the different procedures which have to be used in the psychosocial field. They have even denied scientific status to psychological enquiry because the latter, being concerned with persons and their subjective mental experience, is directed towards making observations of mental events so that measurement and controlled experimentation are not always applicable.

Experimental psychologists have dealt with this by restricting their investigations to objectively observable behaviour to which measurement and control experiments can more readily be applied, thereby, however, ignoring the patient's or person's actual experience (Mair, 1970); this can only be ascertained by asking the subject to tell the observer what he is experiencing (Caine \& Smail, 1969). In so doing the observer has to use awareness of his own subjective experience and apply it to what the patient is communicating to him, a process which depends on sensitive understanding, empathy and controlled identification with the patient in interview situations. Only in this way can the observer or doctor arrive at psychological understanding of what the patient is experiencing and what this experience means to him. In this way much knowledge has been obtained of how human beings at different stages of development from infancy to adulthood react to their psychosocial environment, how they deal with these experiences in their mental life and how these affect their physical reactions and behaviour (Engel⿳亠丷⿵冂丶 1964; Schmale, Meyerowitz \& Tinling, 1970). Objec tive observation of children, experiments based on learning theory and conditioning, and psychoanalytic. studies of children and adults have all contributed to $\overrightarrow{\vec{s}}$ our growing knowledge in this field. More recently it has also become possible to quantify a person's subjective experience by means of special techniques. derived from construct theory using repertory grids (Bannister \& Mair, 1968; Mair, 1970) so thaf measurable data concerning a person's mentais experience are becoming available in addition tọ. data derived from interviews and questionnaires. $\overrightarrow{\vec{H}}$

Psychophysiological study thus depends on en $\vec{\sigma}$ quiry into the subject's inner mental experience and its meaning to him, and on the simultaneous ob $\frac{0}{3}$ servation of associated physiological phenomena and outward behaviour. It differs from the study of in. animate objects because the latter can only be studied from the outside whilst persons need to ber studied, as it were, both from inside and outsides (Guntrip, 1967; Hill, 1970a); progress in the psychoo somatic sphere, therefore, largely depends on de $=$ veloping skills in understanding and observing persons' inner mental experience and on correlatingo these observations with those derived from obsegves? ing their outer behaviour, including physiologiear phenomena.

\section{The role of stress}

Central to the psychosomatic approach is thes knowledge that stressful experience can lead too both psychological and physiological disturbance and the possibility that psychological stress in com bination with biological factors could play a part in $\overrightarrow{\vec{b}}$ the aetiology of a variety of illnesses. As has been pointed out by Vickers (1960), it is important to dis? tinguish clearly between:

(1) The stressful external life situation or 'stressor'한 such as difficulties in interpersonal or social re 3 . lationships, or losses arising from, say, a bereavement, illness, or failure in work situations.

(2) The internal 'stress response' to this externap event which will depend on the meaning the event has for the particular person concerned. This response may take the form of anxiety, guilt, anger $D$ sadness or depression, and it often involves ane. emotional conflict, for example, between socially un $N$ acceptable aggressive impulses and associated guil ho feelings and fear of losing control; and

(3) the observable stressful behaviour evoked byew this response. This may take the form of realistic action but, failing this, it can lead to a multiplicity of inappropriate behaviour patterns, including un $\bar{D}$ controlled aggressive or sexual behaviour, delin ${ }^{+}$ quency, addiction, compulsive overeating, overt psychiatric illness, for example, conversion hysteria $\frac{O}{\vec{D}}$ 
anxiety states, depressive reactions or suicidal attempts; or any of the functional psychosomatic reactions like enuresis, functional diarrhoea, vomiting or psychogenic pain; or the development, aggravation or relapse of structural organic disease, for example bronchial asthma, dermatitis, duodenal ulcer, or ulcerative colitis, to mention only a few.

Both in clinical work and in research a careful assessment of these three components of stress is essential. The nature of the external stressful situation can only be assessed by getting a detailed account of the patient's life situation at the time of onset of his illness. In order to understand his inner stressful response to this situation it is essential to enquire into the meaning the external event had for him at the time; this depends on getting to know what sort of person he is and what his habitual coping responses (Lazarus, 1966) and defence mechanisms are, and how these have been shaped in the course of his development from childhood to the present day. A detailed biographical history is, therefore, required in addition to sensitive understanding of his attitudes and behaviour in the interview situation itself.

The stress behaviour is of course easily observable if it takes the form of an overt behaviour disturbance or of a disease process but many of the physiological changes evoked by stress require detailed observation using physiological and biochemical measurements. These physiological changes need to be correlated with simultaneous enquiry into the patient's subjective experience; in the case of illness and when the question arises whether stress may have played a part alongside biological factors in starting off or aggravating a disease process, the timerelationship between the stressful event, the nature of the patient's response to it and the disease-onset need to be explored in detail. Only in this way can an answer be given to the basic question whether or not stress factors were involved, and why this particular patient has developed this particular illness at this particular time in his life. In this way it may emerge that a variety of apparently disconnected illnesses occurring in the same person may not be totally independent disease entities but may represent different types of stress responses. Thus, enuresis in childhood, ulcerative colitis in early adult life and perhaps a depressive illness in middle age may all turn out to be varying stress responses in a vulnerable personality, the actual form of the illness being determined by multiple factors, including genetic and acquired physical ones and emotional conflict related to a variety of stressful situations.

The psychosomatic approach has also taught us that stress in the family may lead to illness in several family members; illness of one of them quite apart from being a stressful experience for the patient himself, often leading to functional overlay, can also be the precipitating factor leading to illness, physical or mental or both, in one or more of the others.

Nor should it be overlooked that whilst a realistic, technically competent and understanding attitude of the doctor will be stress-relieving, the reverse attitude may itself be a stress factor. For example, failure to listen to what the patient wants to express and to understand its meaning, or a rejecting attitude, and excessive physical investigations carried out to exclude physical disease when proper attention should earlier on have been paid to emotional factors, will themselves be stressful experiences which may lead to an aggravation of an existing illness or the development of further stress-induced symptoms.

\section{Psycho-physiological mechanisms}

Knowledge of the anatomical and physiological basis of emotional experience and behaviour and of their effect on visceral function is now sufficiently far advanced (Brain, 1964) to provide at least the beginning of an understanding of the way in which emotional stress may be related to the development of physical and psychiatric illness.

The temporal lobe and parts of the limbic system have been shown, through animal experiments and observations in patients with lesions in these areas, to be intimately connected with emotional experience and outward behaviour (Smythies, 1969; Iversen, 1969). Kluver \& Bucy $(1937,1939)$ demonstrated that bilateral temporal lobectomies in monkeys led to diminution of aggressive behaviour and fear reactions, to compulsive over-eating, hyper-sexuality, and to increased reactivity to visual stimuli and excessive motor activity. Observations on patients with temporal lobe epilepsy and lesions of the temporal lobe have shown that intense emotional experiences and return of vivid memories and affect can be related to temporal lobe function. The functions of the limbic system have been fully reviewed by Adey \& Tokizane (1967). The amygdala in particular appear to be concerned with visceral sensation and increased visceral reactions, presumably through their influence on hypothalamic function, whilst the hippocampus, in addition to being involved in learning and memory, has an inhibitory effect on visceral and endocrine activity. The reticular formation which is concerned with arousal in response to external and internal stimuli is closely involved together with the amygdala and hippocampus in regulating the emotional and behavioural responses to such stimuli.

It is thus becoming easier to conceive in neurophysiological terms how stressful events can, through their influence on the limbic system and reticular formation, and in turn through their influence on the hypothalamus and the pituitary, alter 
the physiological function of peripheral organs, whilst at the same time giving rise to cognitive experience through the connections of the limbic system and reticular formation with higher cortical centres.

The literature on the physiological effects of stress on peripheral organs is extensive and has been reviewed amongst others by Wolf \& Goodell (1968); it will here only be referred to briefly. In the cardiovascular field the influence of discussing painful topics on the blood pressure is well known and has been investigated in interview situations in normotensive and hypertensive subjects by Hambling (1959). Brod (1970) has demonstrated that anxiety evoked by giving subjects difficult arithmetic tasks to perform increases the cardiac output and coronary and forearm blood flow, while renal resistance is increased and the skin blood flow diminished.

The influence of emotional stress on gastric function, well known since Beaumont's (1833) observations on Alexis St Martin, has been investigated in detail by Wolf \& Wolff (1947); more recently Engel, Reichsman \& Segal (1956) have shown in a $1 \frac{1}{2}$-yearold infant with a gastric fistula that the secretion of hydrochloric acid rose whenever she was relating actively with the experimenter, whilst it diminished when she withdrew from him in a state of apprehension or fear.

The reactivity of the blood vessels of the skin to emotional stimuli is apparent from the everyday observation that people blush when they get embarrassed; it has been investigated in detail in patients with urticaria by Graham \& Wolf (1950). Sweat gland activity is increased by anxiety causing a fall in electrical skin resistance which thus serves as a sensitive physiological measure of anxiety (Lader, 1969). That suggestion under hypnosis inhibits the vascular component of the immediate type hypersensitivity response of the skin has been demonstrated by Black (1963).

In the neuro-endocrine field Levi (1968) has demonstrated that the secretion of adrenaline and noradrenaline is increased in response to emotional stimuli, both pleasurable and unpleasurable, for example by being shown sexually provocative films, the amount of change being correlated with the subject's degree of sexual arousal. That stress increases the secretion of corticosteroids is well known (Gibbons, 1968); recently Sachar et al. (1967) have shown that the urinary excretion of 17-hydroxycorticosteroids rose in the course of psychotherapy of depressed patients when they were re-experiencing the painful life situation which had caused their depressive illness; and Wolff et al. (1964) have shown a similar rise of corticosteroid levels in parents who had to face losing a child dying of leukaemia. Emotional stress can also stimulate thyroid activity, as shown by increased plasma levels of protein-气 bound iodine, and it can lead to a rise of plasma $\frac{3}{8}$ levels of free fatty acids and of the sedimentation rate (Levi, 1969).

Whilst the above observations indicate the wide $-\overrightarrow{\bar{c}}$ spread physiological changes which occur in stressful situations their possible pathological significance is $\frac{\bar{\sigma}}{\sigma}$ less clear. It is however of interest that Brady and hiscs. collaborators (Brady et al., 1958; Polish et al., 1962) have been able to produce severe duodenal ulceration in a group of monkeys who had learnt to avoides getting frequent electric shocks by repeatedly and $\overrightarrow{0}$ for long periods pressing a lever whilst none of the $-\overrightarrow{-}$ control group, not provided with such a lever- $-\bar{\sigma}$ pressing device, did. The prolonged avoidance behaviour appears to have been responsible for the 3 development of the duodenal lesion.

Lastly, Miller (1969) has shown that not only. skeletal but also visceral activity which is, of course, 다 under the control of the autonomic nervous system, can be influenced by conditioning procedures, N changes in the desired direction, for example, ao progressive rise or decrease in heart rate in rats. occurring in response to rewards being given for $\square$ spontaneous changes in heart rate. This suggests ac possible mechanism for the fact that when humagrson are rewarded by, say, excessive solicitude whenever $\vec{P}$ they complain of a psychogenic visceral symptoin such as nausea or vomiting, they may 'learn' to de:velop the same visceral symptom repeatedly untiffif becomes an established pattern of behaviour.

\section{Clinical applications \\ General considerations}

In general it follows that the psychosomatic $\overrightarrow{\vec{B}}$ approach stresses the obvious but frequently 3 neglected need to treat the patient rather than his? illness. It emphasizes the fact that most disease? states are of multifactorial origin and that psycho-o social factors should be considered as much as physical ones in every patient. This does not implyo that one or other of these is more important; in fact, in many organic illnesses psychosocial factors mayO turn out not to have any aetiological significance whilst in some of the physiological disorders of func-음 tion the cause may be mainly or entirely psychogenic, $D$ and prolonged search for a non-existent physical cause may distract from the clinically more relevant enquiry into significant psychosocial factors. In many cases it will be more appropriate to enquire 0 into the relative contributions of both these aspects $\mathrm{N}$ and their interaction than to persist in out-of-date controversy as to whether a particular illness iso determined by physical or psychological factors $\bar{\Phi}$ (Wolff, 1970a).

The psychosomatic approach also emphasizes the need to pay greater attention to such questions as

.


why a particular patient has developed a particular illness at a particular time in his life, how he reacts to his disability, how he is likely to respond to physical or psychological investigations and treatment procedures, and how his illness affects other significant people in his family. It pays particular attention to the doctor-patient relationship and its vicissitudes, making use especially of our knowledge of inter-personal, including transference phenomena; in the same context it concerns itself with the role of teamwork, including nurses and social workers, engaged in patient care in hospital practice (Lipowski, 1967; Wolff, 1970b), and in the community.

The psychosomatic aspects involved in renal dialysis and transplant surgery have recently been reviewed by Cramond (1970), and those encountered in intensive care units by Kornfeld (1969). Some of the psychosomatic problems concerning obstetrics and gynaecology have been dealt with by Wengraf (1953) and in the Proceedings of a Conference on Disorders of Sex and Reproduction (Lucas, 1968).

\section{Disorders of physiological function}

It is particularly in this area that the psychosomatic approach has an important role to play as psychosocial stress is likely to be of special importance in these disorders, so that equal attention must be paid to physical and psychological aspects, both in diagnosis and treatment. The importance of emotional conflict and deprivation in children with enuresis has been demonstrated by Douglas (1970) in a study of disrupted families. Hill (1970b) has investigated the role of inter-personal stress in the aetiology of such gastro-intestinal disorders as functional vomiting, diarrhoea and non-organic abdominal pain. In the latter condition in particular, as in other forms of psychogenic pain, underlying depression, identification with deceased or sick relatives and unexpressed feelings of hostility are likely to be of special significance, and detailed psychological enquiry is needed to elicit the underlying psychopathology.

Anorexia nervosa (Bliss \& Branch, 1960; Crisp, 1967) is a particularly good example of a condition in which only an approach embracing detailed consideration of the patient's personality, the family dynamics and physical factors can lead to a correct assessment of the condition in each individual patient, and to appropriate management, involving both the patient and the family.

\section{Structural organic disease}

Physicians still tend to argue whether conditions like bronchial asthma, peptic ulcer or ulcerative colitis should be regarded as psychosomatic disorders or whether they are of purely physical origin. For example, in the case of ulcerative colitis some authors have found evidence supporting the view that personality factors and emotional conflict situations are of aetiological significance (Lindemann, 1949; Paulley, 1950; Groen \& van der Valk, 1964) whilst Feldman et al. (1967) failed to find any significant differences in personality make-up or precipitating events between a group of ulcerative colitis patients and a control group; however, their control group was inadequate because it mainly consisted of other patients suffering from gastrointestinal disorders in whom psycholog:cal factors may also have been present, nor was the question of the meaningfulness of the supposedly stressful life events to the patients adequately explored. The relative importance of physical and psychological aspects of treatment of ulcerative colitis patients has been critically reviewed recently by O'Connor (1970).

It seems clear that in ulcerative colitis as in bronchial asthma (Pinkerton \& Weaver, 1970), rheumatoid arthritis (Modofsky, 1970) and others the question to be answered is not whether the condition is psychologically or physically determined but what part each of these factors play in the individual patient and how their interaction affects the onset and course of the disease. Only such a combined psychophysiological approach is likely to lead to scientifically acceptable findings in this field.

\section{Psychiatric disorders}

The psychosomatic approach does, of course, apply to psychiatry quite as much as to any of the other branches of medicine, and possibly even more so. In fact the relation between brain function and behaviour is of special concern to psychiatrists, and so is the relationship of the individual to his psychosocial environment, in as far as mental disorders, unless directly due to organic cerebral disease, largely result from stress in interpersonal relationships and consequent disturbance of intra-psychic function.

Anxiety states are an example of a common disorder which develops in people who, as a result of adverse influences in childhood have been left with undue vulnerability to stress, and who therefore react with abnormal degrees of anxiety to stressful events later in life; the numerous physiological disturbances which form part of an anxiety state are well known, and one or other of these rather than his mental symptoms may constitute the patient's presenting symptom.

Depressive illnesses are best looked at from a psychosomatic point of view (Whybrow \& Mendels, 1969). Freud (1917) first drew attention to the relationship between mourning and depression, and serious losses like bereavements are in fact common stressful events precipitating a depressive illness (Parkes, 1964; Birtchnell, 1970). Some of the more serious manifestations of depression like sleep 
disturbance, anorexia, weight loss and the persistent depressive state or posture (Hill, 1968) themselves appear to be maintained by physiological changes in the brain, such as depletion of catecholamines (Schildkraut, 1965). In this sense the brain itself can be looked upon as the target organ which in certain predisposed individuals may be more likely to react to stress with the consequent development of a depressive illness, than in others. Looked at in this way the artificial distinction between reactive and endogenous types of depressive illnesses resolves itself, all depressions forming one continuum (Kendell, 1968), and the question to be answered in each case is to what extent somatic or endogenous factors, and to what extent psychosocial or exogenous factors have jointly played their part in producing the illness.

Similarly, the brain can be seen as the psychosomatic target organ in schizophrenic illnesses, there now being adequate statistical evidence on the one hand to support the hypothesis that genetic aspects (Shields, 1967) play at least some part as predisposing factors, whilst on the other hand Brown \& Birley (1968) have clearly demonstrated the importance of precipitating stressful life events during the 3 weeks immediately preceding the acute onset or relapse of the illness.

The psychosomatic approach has thus resolved some of the controversies concerning the aetiology of depression and schizophrenia, in each case physical changes in the brain being evoked by psychosocial stress in individuals who are predisposed to one or other of these disorders by genetic factors or faulty personality development earlier in life. In these and other psychiatric disorders a psychosomatic approach to treatment is equally important, physical procedures having to be combined with social measures and psychotherapy.

\section{Implications for medical education}

If the psychosomatic approach to the whole field of medicine is to become an integral part of medical practice it is essential to make students familiar with this approach throughout their medical education. The introduction of courses in the behavioural sciences in medical shools is providing an opportunity of making students aware of the psychological and social aspects of health and illness; but it is important that such courses should be orientated towards clinical practice instead of making even further demands on them by expecting them to acquire theoretical knowledge of those aspects of psychology and social medicine which are not directly relevant to their future work. Emphasis needs to be placed on understanding human attitudes and behaviour, the nature of interpersonal relationships and the individual's place in society. Students need to be taught the basis of psychophysical relationships and such teaching should be integrated with instruction iñ physiology, biochemistry and anatomy. During the clinical years they need to learn how to interview patients and to become more sensitive to their. patients' reactions and how to elicit the relevant psychosocial aspects through obtaining detailed biographical histories (Wolff, 1967). Although at thepresent stage psychiatrists are likely to play a majokn role in these aspects of medical education, together with clinical psychologists and medical sociologists it is to be hoped that ultimately all teachers of mediess cine, including general practitioners, will contribute equally, not only through formal teaching but by providing an example of medical practice with whichw the students can identify as they pass through the various departments in the course of their education. Only in this way will future doctors be adequately. prepared to combine their scientific knowledge with the kind of attitude to patients which the psycho-r somatic approach entails.

\section{References}

AdEY, W.R. \& Tokizane, T. (Editors) (1967) Structure and function of the limbic system. Progress in Brain Research Vol. 27.

Alexander, A. \& French, T.M. (1948) Studies in Psyctho somatic Medicine. Ronald Press, New York.

Alexander, F. FRench, T.M \& POLlock, G.H Psychosomatic Specificity. Vol. 1. Experimental Study and Results. University of Chicago Press, Chicago and Londo

BANNISTER, D. \& MAIR, J.M.M. (1968) The Evaluation. of Personal Constructs. Academic Press, London and New York.

BEAUMONT, W. (1833) Experiments and Observations on the Gastric Juice and the Physiology of Digestion. Allen Plattsburgh.

BirTChNELL, J. (1970) Depression in relation to early and흠 recent parent death. British Journal of Psychiatry, 116, 299.3

BLACK S. (1963) Inhibition of the immediate type hypersensitivity response by direct suggestion under hypnosis. British Medical Journal, 1, 925.

Buiss, E.L. \& BRANCH, C.H.H. (1960) Anorexia Nervosa. Hoe-흘 ber, New York.

Brady, J.V., Porter, R.W., Conrad, D.G. \& Mason, J.W. (1958) Avoidance behaviour and development of gastro duodenal ulcers. Journal of the Experimental Analysis of Behavior, 1, 69.

BraIN, LoRD (1964) Psychosomatic medicine and the brain- 0 mind relationship. Lancet, ii, 325.

BReuer, J. \& Freud, S. (1895) Studies on Hysteria, standard $D$ edition, Vol. 2. (1955). Hogarth Press, London.

BROD, I. (1970) Psychological influences on the cardiovascular system. In: Modern Trends in Psychosomatic o Medicine, 2 (Ed. by O. W. Hill), p. 53. Butterworths, London.

Brown, G.W. \& BirLeY, J.L.T. (1968) Social change and the N onset of schizophrenia. Journal of Health and Social $\underbrace{\omega}_{\sigma}$
Behaviour, 9, 203.

Caine, T.M. \& Smail, D.J. (1969) The Treatment of Mentale Illness. University of London Press, London.

Cramond, W.A. (1970) The psychological problems of renal $\stackrel{?}{?}$ dialysis and transplantation. In: Modern Trends in Psychosomatic Medicine 2 (Ed. by O. W. Hill), p. 278. Butterworths, London. 
Crisp, A.H. (1967) Anorexia nervosa. Hospital Medicine, 1, 713.

Douglas, J.W.B. (1970) Broken families and child behaviour. Journal of the Royal College of Physicians, London, 4, 203.

Dunbar, F. (1943) Psychosomatic Diagnosis. Hoeber, New York and London.

Engel, G.L. (1964) Psychological Development in Health and Disease. Saunders, Philadelphia and London.

ENGEL, G.L. (1967) The concept of psychosomatic disorder. Journal of Psychosomatic Research, 11, 3.

Engel, G.L., Reichsman, F. \& Segal, H.L. (1956) A study of an infant with a gastric fistula. I. Behaviour and the state of total hydrochloric acid secretion. Psychosomatic Medicine, 18, 374.

Feldman, F., Cantor, D., Soll, S. \& Bachrach, W. (1967) Psychiatric study of a consecutive series of 34 patients with ulcerative colitis. British Medical Journal, 3, 14.

FREUD, S. (1917) Mourning and Melancholia, standard edition, Vol. 14. (1957), p. 237. Hogarth Press, London.

GibBons, J.L. (1968) The adrenal cortex and psychological distress. In: Endocrinology and Human Behaviour (Ed. by R. P. Michael), p. 220. Oxford University Press, London.

GrahaM, D.T. \& Wolf, S. (1950) The pathogenesis of urticaria. Experimental study of life situations, emotions and cutaneous vascular reactions. Journal of the American Medical Association, 143, 1396.

GROEN, J.J. \& VAN DER VALK, J.M. (1964) Psychosomatic aspects of ulcerative colitis. In: Psychosomatic Research (Ed. by J. J. Groen), p. 32. Pergamon Press, Oxford.

GUNTRIP, H. (1967) The concept of psychodynamic science. International Journal of Psychoanalysis, 48, 32.

Hambling, J. (1959) Essential hypertension. In: The Nature of Stress Disorder, p. 17. Hutchinson Medical Publication, London.

Harre, R. (1970) The Principles of Scientific Thinking. MacMillan, London.

Hill, D. (1968) Depression: disease, reaction or posture? American Journal of Psychiatry, 125, 445.

HILL, D. (1970a) On the contributions of psychiatry to medicine: mechanisms and meaning. British Journal of Psychiatry, 117, 609.

HILl, O.W. (1970b) Functional vomiting, abdominal pain and diarrhoea. In: Modern Trends in Psychosomatic Medicine 2 (Ed. by O. W. Hill), p. 147. Butterworths, London.

IVERSEN, S.D. (1969) Studies of the temporal lobe in monkeys and baboons. In: Current Problems in Neuropsychiatry (Ed. by R. N. Herrington), p. 16. British Journal of Psychiatry, Special Publ. No. 4.

KENDELL, R.E. (1968) The problem of classification. In: Recent Developments in Affective Disorders. (Ed. by A. Coppen and A. Walk), p. 15. British Journal of Psychiatry, Special Publication No. 2.

KLUVER, H. \& BuCY, P.C. (1937) Psychic blindness and other symptoms following bilateral temporal lobectomy in rhesus monkeys. American Journal of Physiology, 119, 352.

KLuver, H. \& BuCY, P.C. (1939) Preliminary analysis of functions of temporal lobes in monkeys. Archives of Neurology and Psychiatry, 42, 979.

KORNFELD, D.S. (1969) Psychiatric view of the intensive care unit. British Medical Journal, 1, 108.

LADER, M.H. (1969) Psychophysiological aspects of anxiety. In: Studies of Anxiety (Ed. by M. H. Lader), p. 53. British Journal of Psychiatry, Special Publication No. 3.

Lazarus, R.S. (1966) Psychological Stress and the Coping Process. McGraw Hill, New York.

LEVI, L. (1968) Sympatho-adrenomedullary activity, diuresis and emotional reactions during visual sexual stimulation in females and males. Reports from the Laboratory for Clinical Stress Research, No. 3, Karolinska Institute, Stockholm.
LEVI, L. (1969) Neuro-endocrinology of anxiety. In: Studies of Anxiety. (Ed. by M. H. Lader), p. 40. British Journal of Psychiatry, Special Publication No. 3.

LewIS, A. (1967) Aspects of psychosomatic medicine. In: Inquiries in Psychiatry, p. 193. Routledge and Kegan Paul, London.

Lindemann, E. (1949) Ulcerative colitis. In: Proceedings of the Association of Research in Nervous Disorders. Monograph on Stress and Bodily Disease, New York.

LIPOWSKI, Z.J. (1967) Review of consultation psychiatry and psychosomatic medicine. I. General principles. Psychosomatic Medicine, 29, 153.

LIPOWSKI, Z.J. (1968) Review of consultation psychiatry and psychosomatic medicine. III. Theoretical Issues. Psychosomatic Medicine, 30, 395.

LuCAs, C.J. (Editor) (1968) Disorders of sex and reproduction. Proceedings of a Conference of the Society for Psychosomatic Research. Journal of Psychosomatic Research, 12, 1.

MaIR, J.M.M. (1970) The person in psychology and psychotherapy: an introduction. British Journal of Medical Psychology, 43, 197.

Miller, N.E. (1969) Learning of visceral and glandular responses. Science, 163, 434.

MoldofsKy, H. (1970) The significance of emotions in the course of rheumatoid arthritis. In: Modern Trends in Psychosomatic Medicine 2 (Ed. by O. W. Hill), p. 217. Butterworths, London.

O'CoNNOR, J.F. (1970) A comprehensive approach to the treatment of ulcerative colitis. In: Modern Trends in Psychosomatic Medicine 2 (Ed. by O. W. Hill), p. 172. Butterworths, London.

PARKes, C.M. (1964) Recent bereavement as a course of mental illness. British Journal of Psychiatry, 110, 198.

Paulley, J. (1950) Ulcerative colitis, a study of 173 cases. Gastroenterology, 16, 566.

Pinkerton, P. \& Weaver, C.M. (1970) Childhood asthma. In: Modern Trends in Psychosomatic Medicine 2 (Ed. by O. W. Hill), p. 81. Butterworths, London.

Polish, E., Brady, J.V., Mason, J.W., ThaCh, J.S. \& NiemecK, W. (1962) Gastric contents and the occurrence of duodenal lesions in the rhesus monkey during avoidance behaviour. Gastroenterology, 43, 193.

Sachar, E.J., Mackenzie, J.M., Binstock, W.A. \& Mack, J.E. (1967) Corticosteroid response to psychotherapy of depressions. Archives of General Psychiatry, 16, 461.

SchildkRAUT, J.J. (1965) The catecholamine hypothesis of affective disorders. American Journal of Psychiatry, 122, 509.

Schmale, A.H. (1969) Somatic expressions and consequences of conversion reactions. New York State Journal of Medicine, 69, 1878.

Schmale, A.H., Meyerowitz, S. \& Tinling, D.C. (1970) Current concepts of psychosomatic medicine. In: Modern Trends in Psychosomatic Medicine 2 (Ed. by O. W. Hill), p. 1. Butterworths, London.

SHIELDS, J. (1967) The genetics of schizophrenia in historical context. In: Recent Developments in Schizophrenia (Ed. by A. Coppen and A. W. Walk), p. 25. British Journal of Psychiatry, Special Publication No. 1.

SMYthies, J.R. (1969) The behavioural physiology of the temporal lobe. In: Current Problems in Neuropsychiatry (Ed. by R. N. Herrington), p. 9. British Journal of Psychiatry, Special Publication, No. 4.

Vickers, G. (1960) The concept of stress in relation to the disorganisation of human behaviour. In: Stress and Psychiatric Disorder (Ed. by J. M. Tanner), p. 3. Blackwell Scientific Publications, Oxford.

Wengraf, F. (1953) Psychosomatic Approach to Gynaecology and Obstetrics. Thomas, Springfield.

WhyBrow. P.C. \& Mendels, J. (1969) Toward a biology of depression: some suggestions from neurophysiology. American Journal of Psychiatry, 125, 1491. 
WittKower, E.D., Cleghorn, J.M., LiPowski, Z.J., Peterfy, G. \& Solyon, L. (1969) A global survey of psychosomatic medicine. International Journal of Psychiatry, 7, 499.

WolfF, H.H. (1967) Influencing students' attitudes towards the emotional aspects of illness. Journal of Psychosomatic Research, 11, 87.

WOLF, H.H. (1968) The psychodynamic approach to psychosomatic disorders: contributions and limitations of psychoanalysis. British Journal of Medical Psychology, 41, 343.

Wolff, H.H. (1970a) The Place of Dynamic Psychiatry in Medicine. Society of Clinical Psychiatrists, Report No. 1. Calver Press, Ipswich.
WolfF, H.H. (1970b) Practice and teaching of psychosomatic్ڤ medicine in general hospitals. In: Modern Trends in Psychosomatic Medicine 2 (Ed. by O. W. Hill), p. 298. Butter-吕 worths, London.

Wolff, C.T., Friedman, S.B., Hoffer, M.A. \& Mason, J.W: (1964) Relationship between psychological defences and mean urinary 17 -hydroxycorticosteroid excretion rates: Psychosomatic Medicine, 26, 576.

Wolf, S. \& Goodell, H. (1968) Harold G. Wolff's Stress and Disease, 2nd edn. Thomas, Springfield.

Wolf, S.G. \& WolfF, H.G. (1947) Human Gastric Function: An Experimental Study of a Man and his Stomach. Oxfordu University Press, London. 